\title{
Correction to: High-fidelity elastic Green's functions for subduction zone models consistent with the global standard geodetic reference system
}

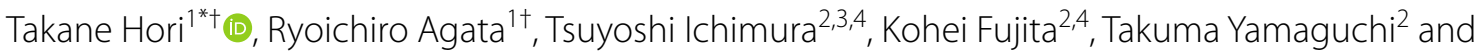
Takeshi linuma'

\section{Correction to: Earth, Planets and Space (2021) 73:41}

https://doi.org/10.1186/s40623-021-01370-y

After the publication (Hori et al. 2021), we found a mistake in calculation of the Green's functions for the Nankai Trough region: the plate convergence direction was incorrectly set. Revised Figs. 5a and 6 shows the results based on the correct simulation setting. Figure $5 \mathrm{~b}$ does not change from the original publication. Because the norm of the estimated slip deficit rate (SDR) is independent of the choice of coordinate of the fault slip in the inversion formulation used in our study, we only see apparent change in the arrows denoting the direction of SDR in Fig. 6. The change of the results does not affect the discussion in the main text.

The original article has been updated.

The original article can be found online at https://doi.org/10.1186/s40623021-01370-y.

\footnotetext{
*Correspondence: horit@jamstec.go.jp

TTakane Hori and Ryoichiro Agata contributed equally to this study

${ }^{1}$ Research Institute of Marine Geodynamics, Japan Agency for Marine

Earth Science and Technology, Yokohama, Kanagawa, Japan

Full list of author information is available at the end of the article
}

\section{Springer Open}

(c) The Author(s) 2021. This article is licensed under a Creative Commons Attribution 4.0 International License, which permits use, sharing adaptation, distribution and reproduction in any medium or format, as long as you give appropriate credit to the original author(s) and the source, provide a link to the Creative Commons licence, and indicate if changes were made. The images or other third party material in this article are included in the article's Creative Commons licence, unless indicated otherwise in a credit line to the material. If material. is not included in the article's Creative Commons licence and your intended use is not permitted by statutory regulation or exceeds the permitted use, you will need to obtain permission directly from the copyright holder. To view a copy of this licence, visit http://creativeco mmons.org/licenses/by/4.0/. 

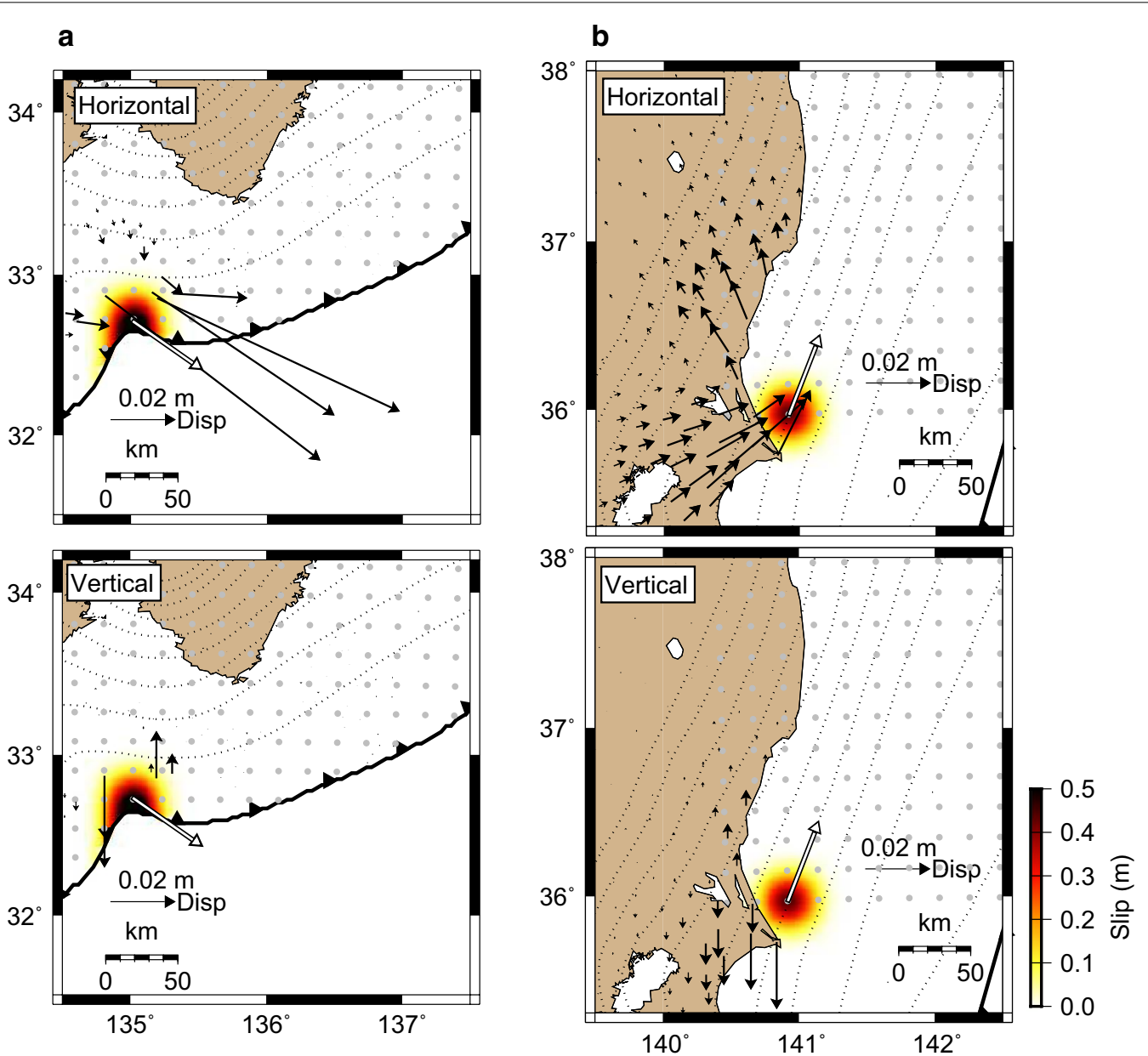

Fig. 5 Examples of GF calculated based on FE modeling. a A unit slip and its response displacement in the direction opposite to the plate convergence in Nankai Trough and $\mathbf{b}$ one in the direction perpendicular to the plate convergence in the Japan Trench subduction zone. Note that unit slip in the location beyond the trench or trough axis is set forcibly zero in $\mathbf{a}$. Gray dots denote the central point of B-spline function shaped slip applied in a subfault. The color map shows slip distribution. The black arrows denote the horizontal (top) and vertical (bottom) surface displacements due to the fault slip. The white arrows denote fault slip directions 


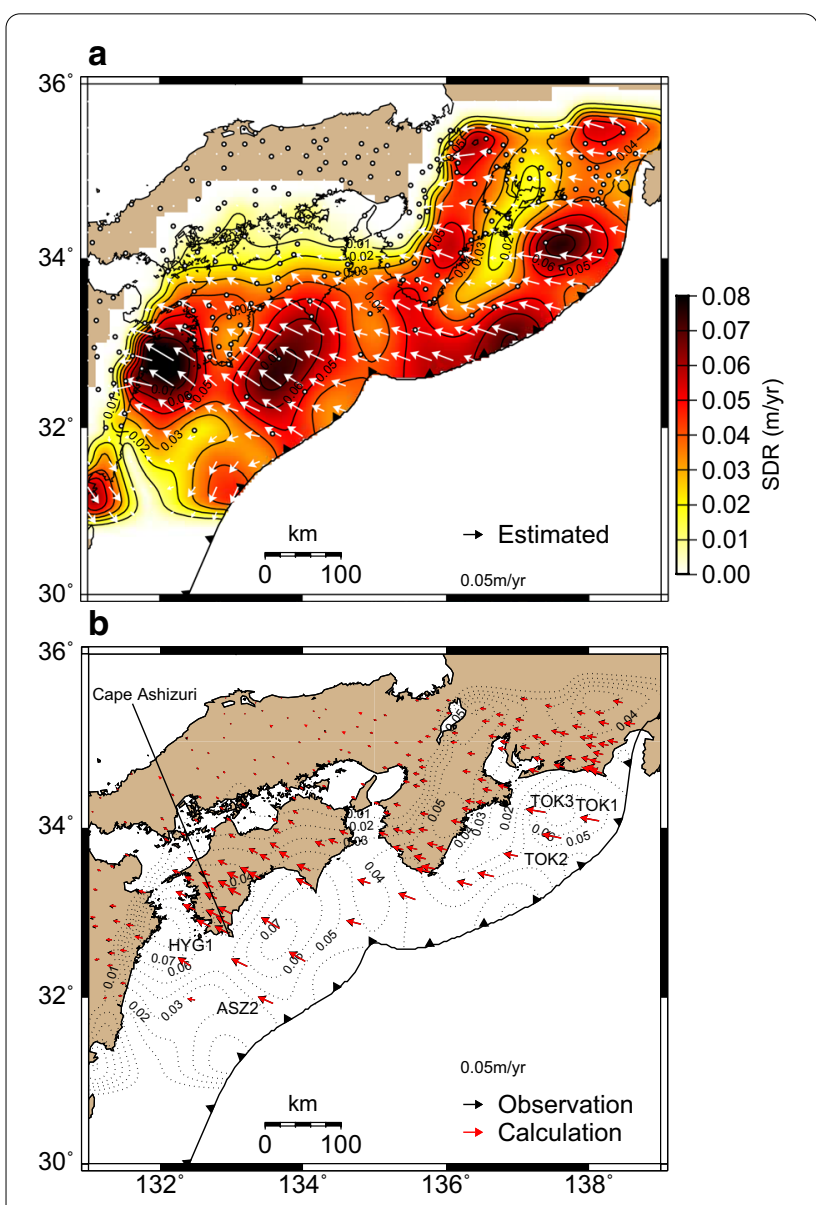

Fig. 6 SDR distribution estimated using the GF library. a Color contour and vectors of estimated SDR. The white dots denote the location of the observation. $\mathbf{b}$ Comparison of observed and calculated velocity in the observation stations. Dotted contour lines denote the norm of the estimated SDR

\section{Acknowledgements}

This study was supported by Post K computer project (Priority issue 3: Development of Integrated Simulation Systems for Hazard and Disaster Induced by Earthquake and Tsunami) and by MEXT as "Program for Promoting Researches on the Supercomputer Fugaku" (Large-scale numerical simulation of earthquake generation, wave propagation and soil amplification: Proposal number hp200126) and used computational resources of Oakforest-PACS provided by The University of Tokyo. This study was also supported by Japan Society for the Promotion of Science (18H05239). Some figures were produced using GMT software (Smith and Wessel 1990).

\section{Author details}

${ }^{1}$ Research Institute of Marine Geodynamics, Japan Agency for Marine Earth Science and Technology, Yokohama, Kanagawa, Japan. ${ }^{2}$ Earthquake Research Institute \& Department of Civil Engineering, The University of Tokyo, Bunkyo-ku, Tokyo, Japan. ${ }^{3}$ Center for Advanced Intelligence Project, RIKEN, Chuo-ku, Tokyo, Japan. ${ }^{4}$ Center for Computational Science, RIKEN, Kobe, Hyogo, Japan.

Published online: 02 April 2021

\section{References}

Hori T, Agata R, Ichimura T et al (2021) High-fidelity elastic Green's functions for subduction zone models consistent with the global standard geodetic reference system. Earth Planets Space 73:41. https://doi.org/10.1186/ s40623-021-01370-y

Smith W, Wessel P (1990) Gridding with continuous curvature splines in tension. Geophysics 55(3):293-305

\section{Publisher's Note}

Springer Nature remains neutral with regard to jurisdictional claims in published maps and institutional affiliations. 